Arch. Met. Geoph. Biokl., Ser. B, 20, 253-260 (1972)

(C) by Springer-Verlag 1972

Department of Geography, University of Michigan, Ann Arbor, Michigan, U.S. A.

\title{
A Synthetic Analysis of Seasonal Influences in the Effects of Land Use on the Urban Thermal Regime
}

\section{Samuel I. Outcalt}

With 2 Figures

Received March 22, 1972

\section{Summary}

A simple digital surface climate simulator is employed as the vehicle for the exploration of some relationships between land-use and the urban climate. Specifically the simulator indicates that the physical roots of the urban "heat island effect" are significantly seasonally variable.

\section{Zusammenfassung}

Eine synthetische Analyse der jahreszeitlich bedingten Einflüsse der Bodennutzung auf das Temperaturregime einer Stadt

Ein einfacher numerischer Simulator des Bodenklimas wurde zur Erforschung des Zusammenhanges zwischen Bodennutzung und Stadtklima verwendet. Im besonderen zeigte dieser Simulator, daß die physikalischen Grundlagen der städtischen "Wärmeinsel" in signifikanter Weise jahreszeitlichen Einflüssen unterliegen.

\section{Introduction}

This report is essentially an appendix to earlier papers in which the land-use dependence of the surface thermal regime was simulated and demonstrated using thermal scan data $[2,3]$. The agreement between the thermal scan material and the simulations indicated that the synthetic,energy transfer system was "mimicking" the real world to such a degree that it was impossible to allocate the diver- 
gence between the synthetic and real world thermal regimes to sampling-experimental or simulator construction error [3]. It follows that some gross information concerning the interaction between land-use and surface climate might be acquired by the application. of the simulator outside "data space" and that this information at least could serve as a basis for hypothesis formulation and experimental design. In this trial application the problem put to the simulator was: Is the physical basis for the urban heat island effect at Ann Arbor seasonally variable?

\section{The General Simulation Process}

The digital computer simulation of surface climate is activated by the acquisition of sixteen boundary conditions (i. e. latitude, solar declination, atmospheric dust content, station pressure, orbital radius vector, surface albedo, precipitable water, sky radiation temperature, mean diurnal temperature, air saturation fraction (RH/ 100), mean diurnal air wind velocity, soil thermal diffusivity, soil volumetric heat capacity, roughness length, soil wet fraction and fraction of terrain in shadow).

The incoming solar radiation is then calculated as a function of latitude, precipitable water, albedo, station pressure, dust content, orbital radius vector and solar declination at 15 minute increments [4]. The soil and atmospheric diurnal damping depths are then calculated. In addition, an adiabatic atmospheric exchange coefficient is computed which is later adjusted for stability by the factor (1. - 16. " $R_{i}$ ), where $\left(R_{i}\right)$ is the Richardson number.

Each of the four components of energy transfer (i. e. net radiation, soil heat flux, sensible heat flux and latent heat flux) is a function of varied combinations of the sixteen boundary conditions in addition to surface temperature. An interval-halving process substitutes surface temperatures into this system of equations until the residual in the sum of the energy exchange components has absolute value of less than $1 \mathrm{mly} / \mathrm{min}$. When this condition exists, the values of the energy exchange components and surface temperature are retained for that time (iteration). This process is repeated at 15 -minutes intervals (96/diurnal cycle). The solution surface temperature is called the equilibrium surface temperature and is that surface temperature which will balance the energy transfer equation at a specific time. It is necessary to run the simulator through one diurnal cycle to set the stage for the second cycle. 
Lag in the surface temperature regime (lagging solar radiation) is produced by the solution of the Fickian diffusion equation at four substrate soil levels between the diurnal damping depth and the surface. A more detailed discussion of the theory of equilibrium temperature calculations is included in an earlier article by this author [2].

\section{Modifications to the General Simulator Specific to Urban Reconnaissance}

The general simulator discussed earlier was modified in the following manner for the urban reconnaissance task:

a) The thermal diffusivity of the substrate material was estimated from the surface wet fraction assuming as end points the thermal properties of concrete-steel (dry) and soil (wet). The volumetric heat capacity was set at $0.5 \mathrm{c}$. g. s. units to produce a linear relationship between diffusivity and conductivity. The scheme is essentially the same one employed by Myrup [8].

b) The silhuette ratio is defined as the ratio of the vertical silhouette area to the horizontal area of a sample tract and is thus identical to Lettau's ratio of the silhouette area to the lot area [7].

c) Obstruction beight is defined as the mean height of obstructions which together make the silhouette area "seen" by beam radiation and the wind [7].

d) The aerodynamic roughness length is computed as one half of the product of the obstruction height and the silhouette ratio [7].

e) The solar radiation incident upon vertical terrain elements was estimated by computing the radiation (beam and hemispherical) on a vertical wall which was rotated normal to the sun's hour angle. This increased the effective radiation intercepting area as the silhouette ratio (the shaded side to the wall is assumed to receive only hemispherical radiation) increased. This rather crude approximation of reality was employed to increase the solar radiation absorption of "optically rough terrain" and was derived from the treatments of beam and diffuse radiation incident on slopes by Lee [6] and Kondrat'yev [5].

f) The thermal radiation flux from a terrain block was reduced using the viewfactor method of Reifsnyder and Lull [9]. The viewfactor is equated with the silhouette ratio, as defined by this author.

g) The fraction of rough terrain in shadow was crudely estimated as the cube of one minus the cosine of the solar zenith angle. This 
yields a large value near sunrise and sunset and rapidly diminishes with increasing solar elevation. The function is an arbitrary one designed to approximate reality in complex "optically rough terrain".

h) The radiant temperature of the sky hemisphere was arbitrarily set at $22^{\circ} \mathrm{C}$ below the mean air temperature as this approximation produced a clear sky net nocturnal thermal radiation flux compatible with field observation.

These modifications permit the parameterization of the optical, aerodynamic and thermal properties of a tract of urban land using only two dimensionless numbers and a length (silhouette ratio, wet fraction and obstruction height).

The surface albedo was set at 20 percent and the infrared emissivity at unity due to an absence of data and a desire to exclude these effects from an initial analysis. In addition the albedo and incoming radiation flux are insufficient for the estimation of the solar radiation absorption of "optically rough" terrain blocks where vertical surfaces intercept the solar beam.

\section{Seasonal Variation}

Having parameterized the landscape the model was interrogated as to seasonal effects. In the simulation the same terrain types were used as in an earlier study with the addition of a woodlot and construction site to build in sufficient statistical freedom to permit a regression analysis of seasonal effects. The same meteorological

Table 1. Terrain Parameters (Independent Variables)

\begin{tabular}{llll}
\hline & Wet fraction & Silhouette ratio & Obstruction height $(\mathrm{cm})$ \\
\hline Farmland $\ldots \ldots \ldots \ldots \ldots \ldots$ & 0.90 & 0.10 & 1500 \\
City Center $\ldots \ldots \ldots \ldots \ldots \ldots$ & 0.01 & 0.30 & 2000 \\
New Subdivision $\ldots \ldots \ldots \ldots$ & 0.70 & 0.10 & 700 \\
Old Residential $\ldots \ldots \ldots \ldots$ & 0.70 & 0.20 & 1500 \\
Woodlot $\ldots \ldots \ldots \ldots \ldots \ldots$ & 1.00 & 0.20 & 1500 \\
Constr. Site $\ldots \ldots \ldots \ldots \ldots$ & 0.10 & 0.05 & 700
\end{tabular}

boundry conditions were used as in the earlier study. Only the mean air temperature was lowered to $10^{\circ} \mathrm{C}$ and the astronomical parameters were altered to simulate a snowfree solstice condition in the winter simulation set [3]. The terrain units used in the simulation are listed in Tab. 1. 
The results of the simulations are presented in Figures 1 and 2 and in Table 2.

Table 2. Simulation Results

\begin{tabular}{|c|c|c|c|c|}
\hline & \multicolumn{2}{|c|}{ Maximum diurnal temp. $\left({ }^{\circ} \mathrm{C}\right)$} & \multicolumn{2}{|c|}{ Diurnal temp. range $\left({ }^{\circ} \mathrm{C}\right)$} \\
\hline & 5 Aug. & 21 Dec. & & \\
\hline Farmland & $25.2(4)$ & $10.9(5)^{1}$ & $6.3(4)$ & $3.7(4)$ \\
\hline City Center & $30.0(2)$ & $13.7(1)^{1}$ & $8.5(3)$ & $4.2(3)$ \\
\hline New Subdivision & $27.9(3)$ & 12.1 (3) & $9.1(2)$ & $5.8(2)$ \\
\hline Old Residential . & $24.8(5)$ & $11.3(4)^{1}$ & $5.4(5)$ & $3.3(5)$ \\
\hline Woodlot & $23.6(6)$ & $10.7(6)$ & $4.4(6)$ & $2.9(6)$ \\
\hline Constr. Site & 35.8 (1) & $13.2(2)^{1}$ & $19.3(1)$ & $6.4(1)$ \\
\hline
\end{tabular}

1 Rank discrepancy, () thermal rank

It is apparent that there are pronounced seasonal effects altering both the phase and amplitude relationships between and among

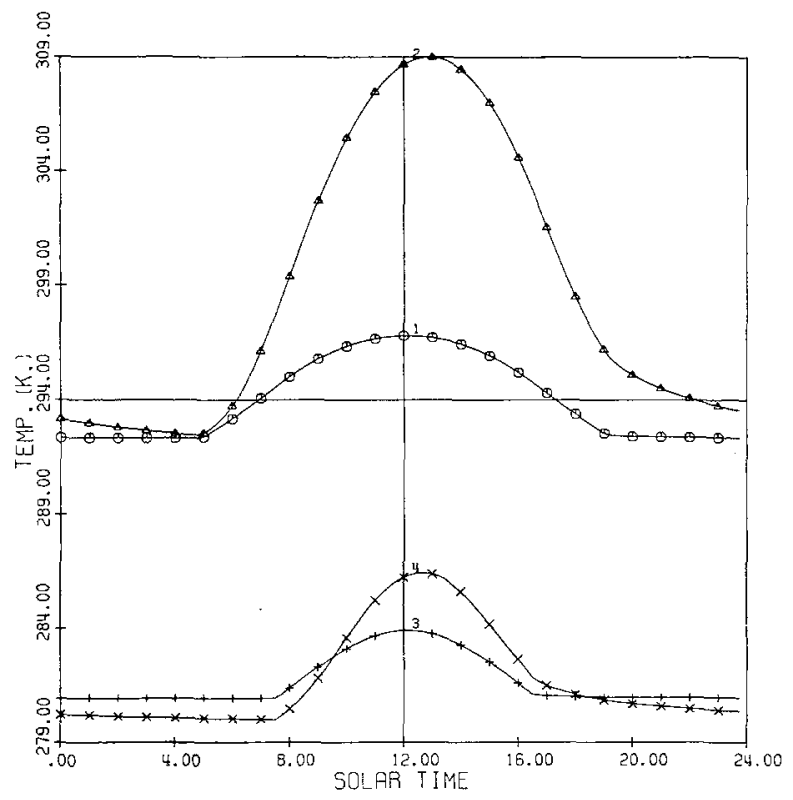

Fig. 1. Simulated thermal contrast between city center and farmland

1 Farmland: 5 August; 2 City Center: 5 August;

3 Farmland: 21 December; 4 City Center: 21 December

the land-use types. The magnitude of these effects is illustrated in Tab. 2 by the variance in the thermal rank of the maximum diurnal 
surface temperature. In an attempt to highlight the physical roots of these discrepancies a regression analysis of the seasonal sets was run using the diurnal maximum $(T m)$ and thermal range $(T r)$ as

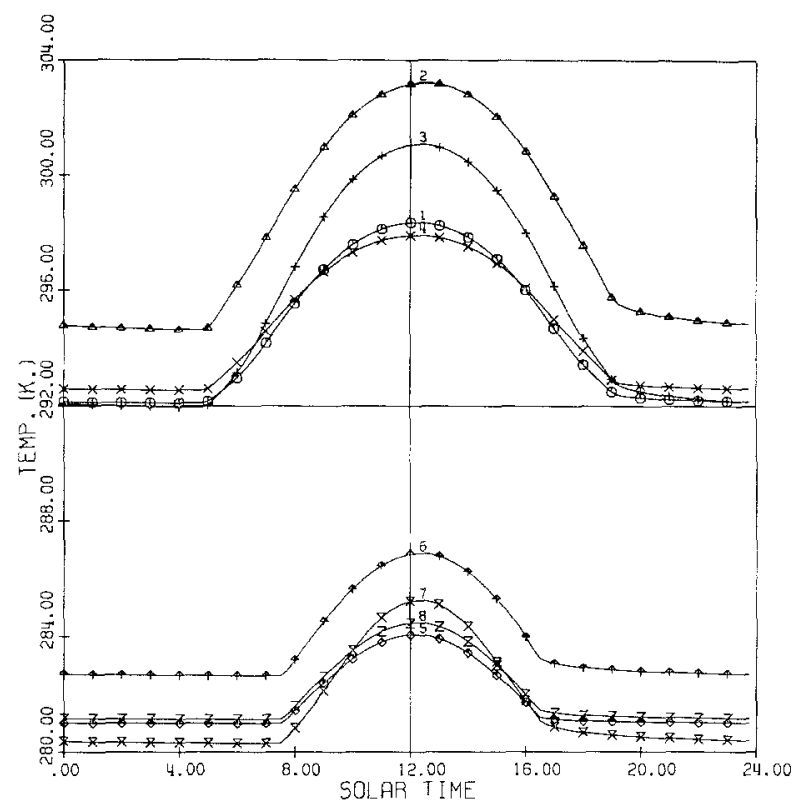

Fig. 2. Simulated land use thermal contrast

5 August: 1 Farmland, 2 City Center, 3 New Subdivision, 4 Old Residential 21 December: 5 Farmland, 6 City Center, 7 New Subdivision, 8 Old Residential

the dependent variables and the wet fraction (W), silhouette ratio $(S)$ and obstacle height $(O)$ as independent variables. The equations of best fit had the following forms.

$$
\begin{aligned}
& T m=a+b_{w} W+b_{s} S+b_{o} O \text { max. equation } \\
& T r=a+b_{w} \mathrm{~W}+b_{s} S+b_{o} O \text { range equation }
\end{aligned}
$$

If one employs the null hypothesis that in the face of no seasonal effects the coefficient slopes $(b)$ should not vary seasonally to a significant degree it is possible to analyse the variance using a student's $t$-test design. In each case it is possible to set up two alternate null hypothesis using the standard error of the summer and winter slope of best fit for the individual land-use parameters. The results of these manipulations are summarized in Tab. 3. 
Table 3. Seasonal Analysis

\begin{tabular}{|c|c|c|c|}
\hline & $b w$ & $b_{s}$ & bo \\
\hline \multicolumn{4}{|l|}{ I. Max. Diurnal Temperature } \\
\hline 1. Summer .......... & -10.3 & -18.80 & $0.1166 \cdot 10^{-2}$ \\
\hline 2. Winter $\ldots \ldots \ldots \ldots$ & -2.8 & 3.02 & $0.064 \cdot 10^{-2}$ \\
\hline 3. Diff. $(1-2)^{1}$ & 7.22 & 21.82 & $0.1102 \cdot 10^{-2}$ \\
\hline 4. $S_{b}$ summer $\ldots \ldots \ldots$ & 1.184 & 10.63 & $0.1865 \cdot 10^{-2}$ \\
\hline 5. $S_{b}$ winter $\ldots \ldots \ldots \ldots$ & 0.405 & 3.63 & $0.064 \cdot 10^{-2}$ \\
\hline 6. to summer $(3 / 4)^{2} \ldots \ldots$ & $6.3^{4}$ & 2.3 & 0.6 \\
\hline 7. $t_{b}$ winter $(3 / 5) \ldots \ldots$ & $18.0^{4}$ & $6.0^{4}$ & 1.7 \\
\hline \multicolumn{4}{|c|}{ II. Diurnal Temperature Range } \\
\hline 1. Summer ........... & -10.37 & -32.37 & $-0.1691 \cdot 10^{-2}$ \\
\hline 2. Winter & -2.09 & 2.85 & $-0.2673 \cdot 10^{-2}$ \\
\hline 3. Diff. $(1-2)^{1} \ldots \ldots \ldots$ & 8.28 & 35.22 & $0.0982 \cdot 10^{-2}$ \\
\hline 4. $S_{b}$ summer $\ldots \ldots \ldots$. & 2.50 & 18.33 & $0.3217 \cdot 10^{-2}$ \\
\hline 5. $S_{b}$ winter $\ldots \ldots \ldots \ldots$ & 0.45 & 4.07 & $0.071 \cdot 10^{-2}$ \\
\hline 6. $t_{b}$ summer $(3 / 4)^{2} \ldots$ & 3.3 & 1.9 & 0.3 \\
\hline 7. to winter $(3 / 5)^{2} \ldots \ldots$ & $18.3^{4}$ & $8.6^{4}$ & 1.4 \\
\hline 1 Row 1 minus row 2 & \multicolumn{3}{|c|}{3 Row 3 divided by row 5} \\
\hline${ }^{2}$ Row 3 divided by row 4 & \multicolumn{3}{|c|}{${ }^{4}$ Reject null hypothesis at $5 \%$ level [1] } \\
\hline
\end{tabular}

The slope analysis clearly demonstrates that we may accept the hypothesis that the impact of wet fraction and silhouette ratio on the thermal regimes at Ann Arbor is seasonally variable within the model context. Further, this transfer of influence is physically reasonable as the evaporation capacity of the air during the winter months is diminished whereas the solar radiation absorption on vertical surfaces is enhanced. The non-significant effect of the obstruction height is also reasonable as this parameter is used only in the computation of the atmospheric exchange coefficient. In short the model indicates the realm of response expected as the influence of evaporation diminishes and the relative magnitude of vertical surface beam radiation increases during the colder low sun season. It is therefore implied that the physical basis of the heat "island effect are both geographically and temporally variable and that an explanation suitable for London in winter may not be suitable for New Orleans in winter or even London in summer. Thus, this primitive model indicates the danger of "universal hypothesis" for the heat island phenomena and suggests the probable response range of seasonal effects. Further, experimental design restrictions are implied by the time dependent simulation graphs as the approximate times of maximum contrast are indicated. 
This extention of normal simulation-sensitivity testing is used to demonstrate the capacity of a deterministic physical model to suggest hypothesis and experimental designs at the early stages of empirical investigations. As process information becomes available it can be woven into the model structure to test alternative hypotheses against observed spatial variation. Lastly, it should be stressed that the effects reported here were generated without consideration of fossil fuel consumption and pollution of the urban atmosphere and are the products of land-use variation alone.

\section{References}

1. Crow, E. L., F. A. Davis, and M. W. Manfield: Statistics Manual. Dover Publications, p. 179.

2. Outcalt, S.: The Development and Application of a Simple Digital Surface Climate Simulator. J. Applied Meteorol. 11, 629-636 (1972).

3. Outcalt, S.: A Reconnaisance Experiment in the Mapping and Modeling of the Effects of Land-Use on Urban Thermal Regimes. J. Appl. Meteorol. (in press).

4. Gates, D.: Energy Exchange, in the Biosphere. Harper \& Row Biological Monographs, 151 pp. (1962).

5. Kondrat'yev, K. Ya.: Radiative Heat Exchange in the Atmosphere. Oxford: Pergamon Press, 1955.

6. Lee, R.: Evaluation of Solar Beam Irradiation as a Climatic Parameter of Mountain Watersheds. Hydrology Paper, Colorado State University, Fort Collins, No. 2, 50 pp. (1963).

7. Lettau, H.: Note on Aerodynamic Roughness Parameter Estimation on the Basis of Roughness Element Description. J. Applied Meteorol. 8, 828-832 (1969).

8. Myrup, L. O.: A Numerical Model of the Urban Heat Island. J. Applied Meteorol. 8, 908-918 (1969).

9. Reifsnyder, W. E., and H.W. Lull: Radiant Energy in Relation to Forests. Techn. Bull. No. 1344, USDA, 1965, 111 pp.

Author's address: Dr. Samuel I. Outcalt, Department of Geography, University of Michigan, Ann Arbor, MI 48104, U. S. A. 